University of Tennessee Health Science Center UTHSC Digital Commons

Spring 5-2019

\title{
Barriers to Patient Electronic Portal Usage
}

Debbie Hoza

University of Tennessee Health Science Center

Follow this and additional works at: https://dc.uthsc.edu/hiimappliedresearch

Part of the Health and Medical Administration Commons, and the Health Information Technology Commons

\section{Recommended Citation}

Hoza, Debbie, "Barriers to Patient Electronic Portal Usage" (2019). Applied Research Projects. 59. . https://doi.org/10.21007/chp.hiim.0064

https://dc.uthsc.edu/hiimappliedresearch/59

This Research Project is brought to you for free and open access by the Department of Health Informatics and Information Management at UTHSC Digital Commons. It has been accepted for inclusion in Applied Research Projects by an authorized administrator of UTHSC Digital Commons. For more information, please contact jwelch30@uthsc.edu. 


\author{
Barriers to Patient Electronic Portal Usage \\ Debbie Hoza, RPh \\ University of Tennessee Health Science Center \\ Master of Health Informatics and Information Management \\ Advisor: Dr. Sajeesh Kumar \\ IRB\# 18-06128-XM Approval Date 02/08/2019
}

May 2019 


\section{Table of Contents}

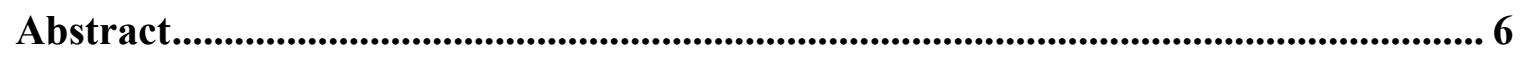

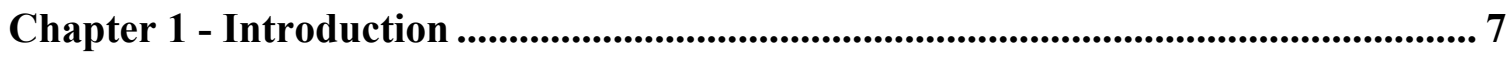

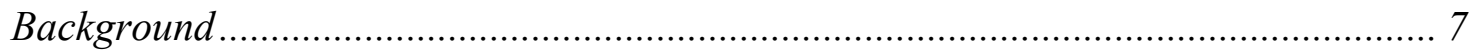

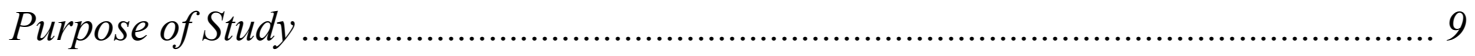

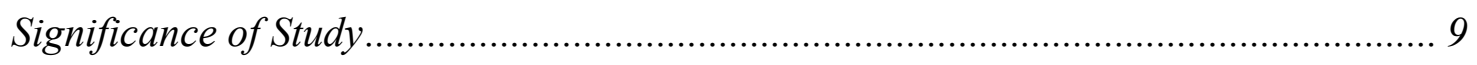

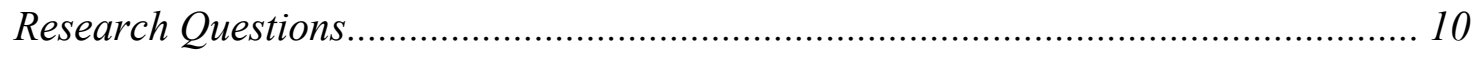

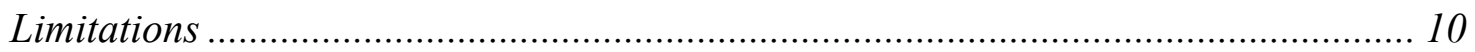

Chapter 2 - Review of the Literature ............................................................................ 11

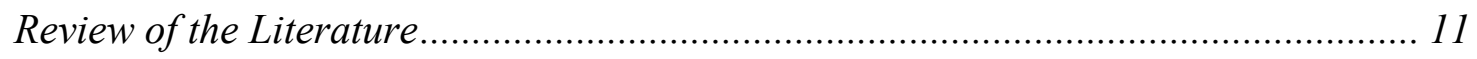

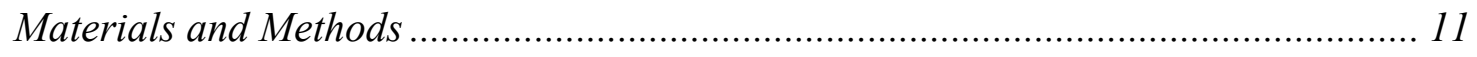

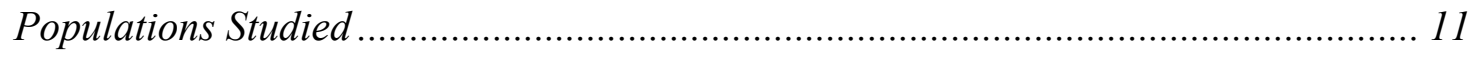

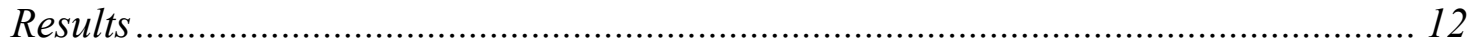

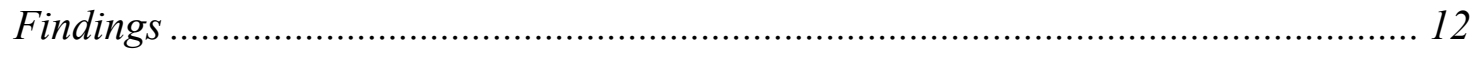

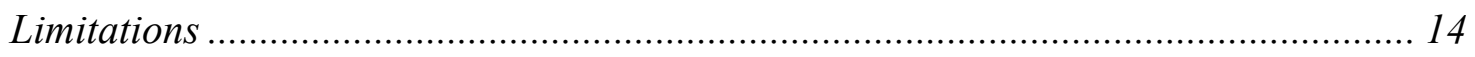

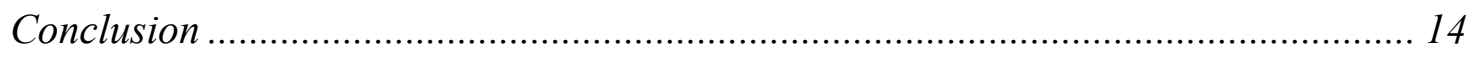

Chapter 3 - Methodology ........................................................................................................... 15

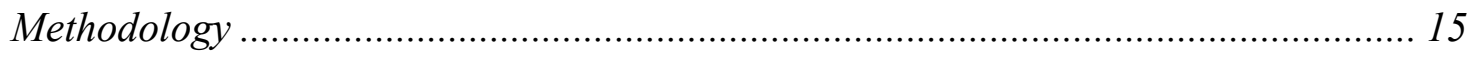

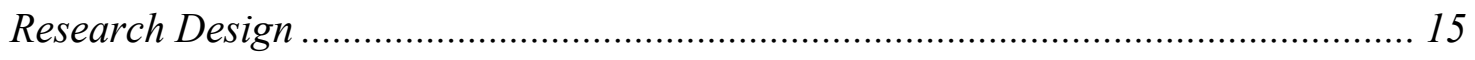




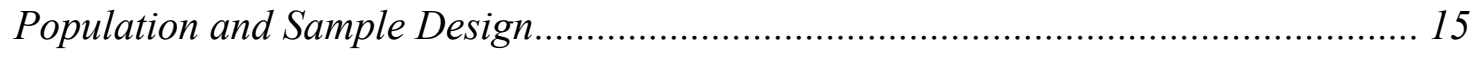

Data Collection Procedures .................................................................................. 15

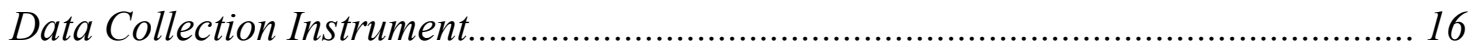

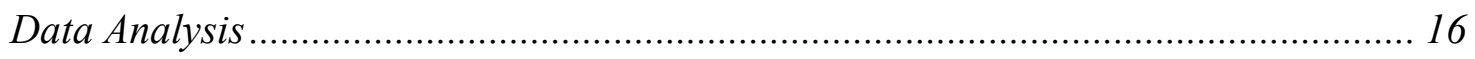

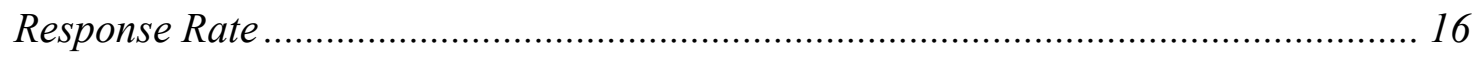

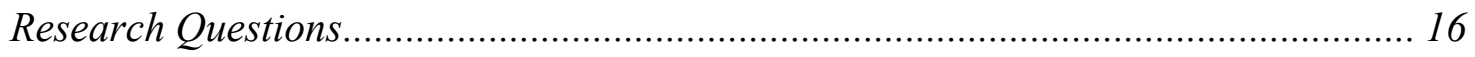

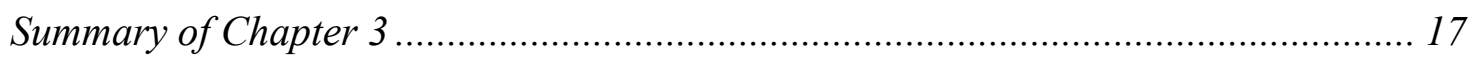

Chapter 4 - Results....................................................................................................................... 18

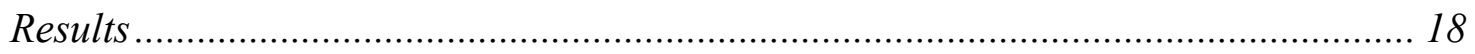

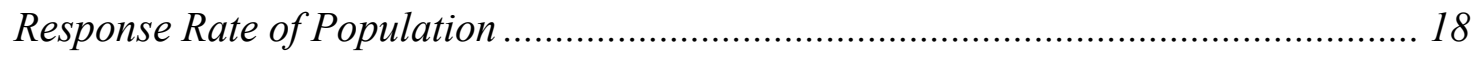

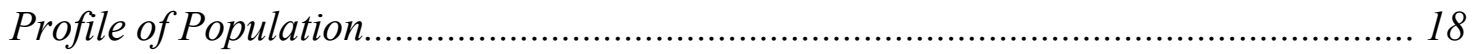

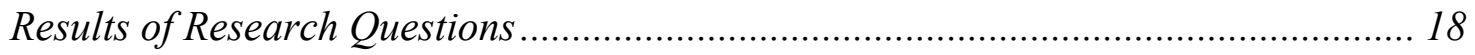

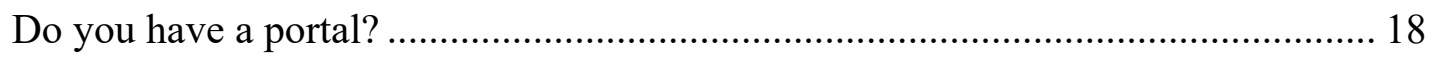

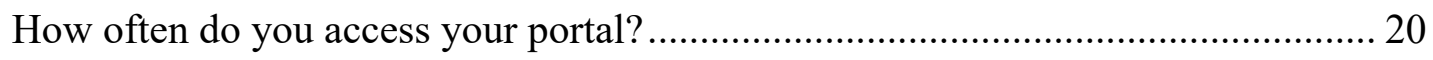

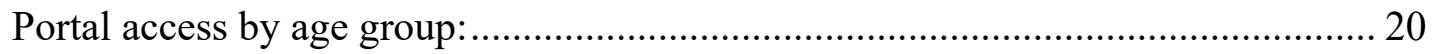

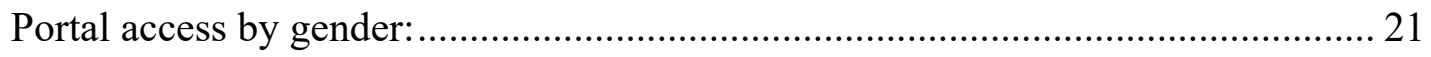

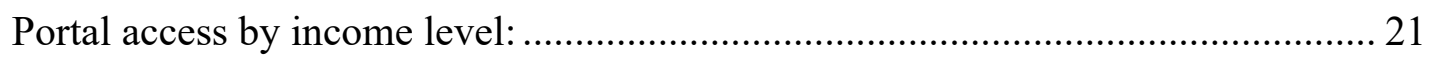

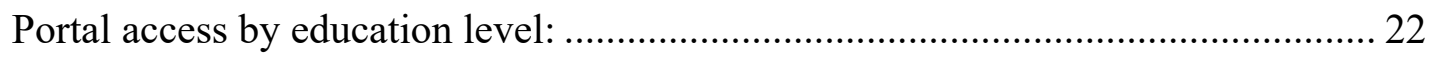

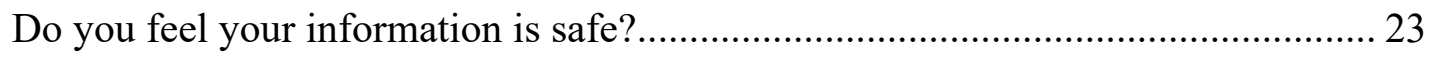

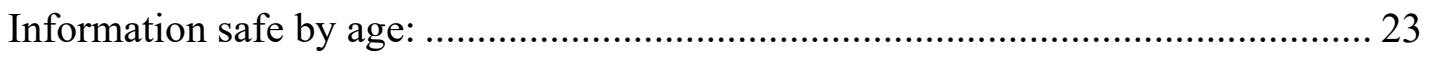

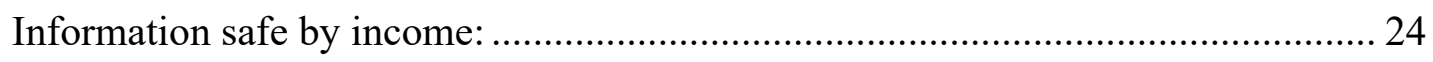

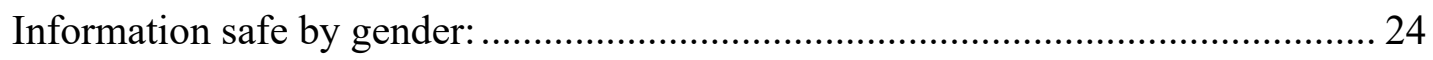




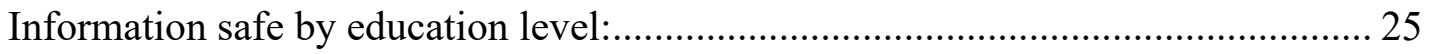

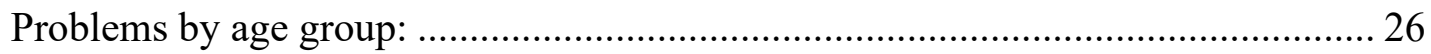

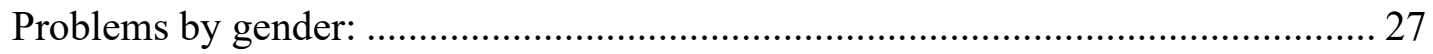

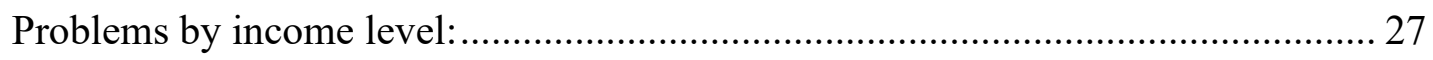

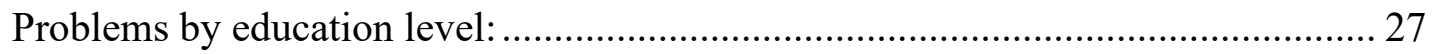

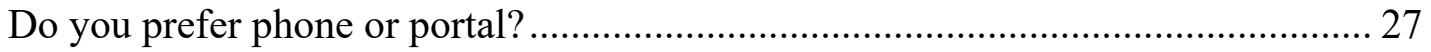

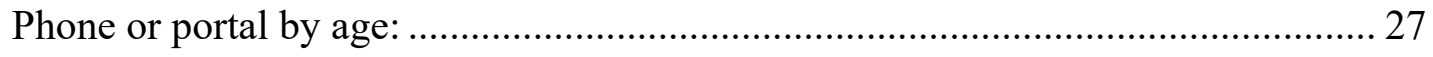

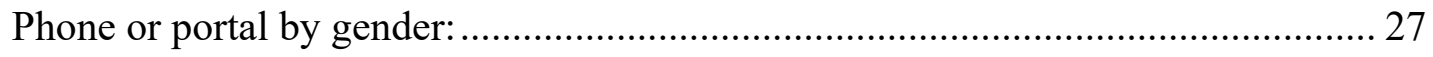

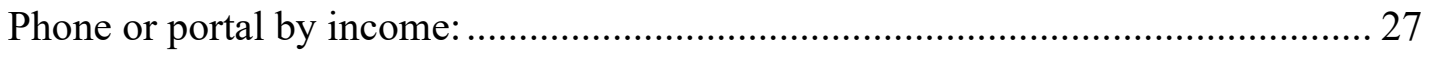

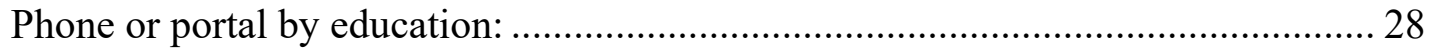

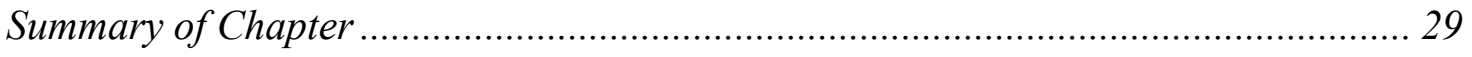

Chapter 5 - Conclusions and Recommendations..........................................................30

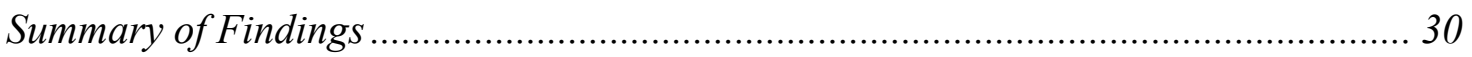

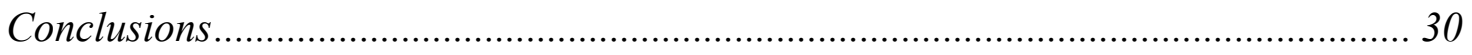

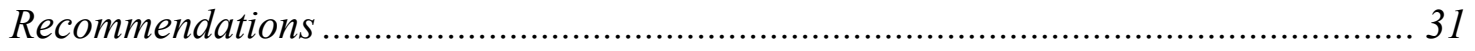

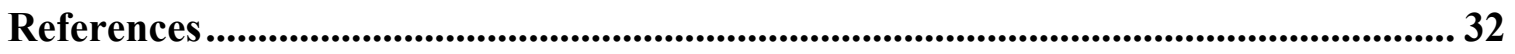

\section{List of Tables}

Table 1 - Comparison of Studies Reviewed ................................................................ 13

Table 2 Problems Using the Portal ………………….................................................. 26

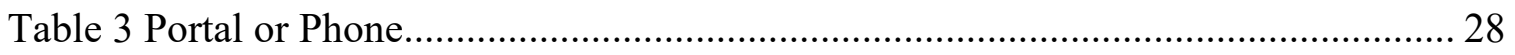




\section{List of Figures}

Graph 1 Do You Have a Portal? By Age Group....................................................... 18

Graph 2 Do You Have a Portal? By Gender.............................................................. 19

Graph 3 Do You Have a Portal? By Income Level ..................................................... 19

Graph 4 Do You Have a Portal? By Education Level ............................................... 20

Graph 5 How Often Portal Accessed in Six Months - By Age.................................... 21

Graph 6 How Often Portal Accessed by Gender ...................................................... 21

Graph 7 How Often Portal Accessed by Income Level ........................................... 22

Graph 8 How Often Portal Accessed by Education Level.......................................... 22

Graph 9 Information Safe? By Age Group ............................................................... 23

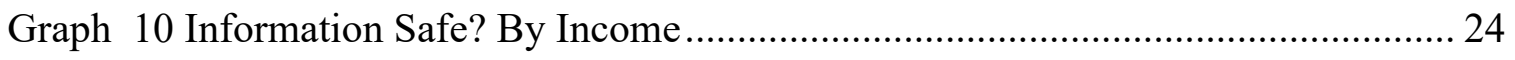

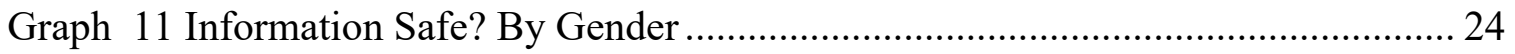

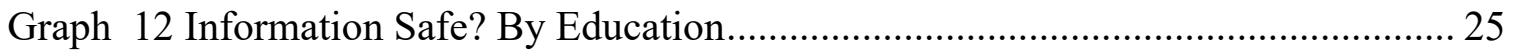




\begin{abstract}
This paper focuses on the barriers that patients have as to why they do not use their electronic patient portal. The literature suggests that the age and socioeconomic status of the individual has a big impact on the use of the electronic portals. A review of the literature showed that all populations have not been represented. This study surveys a broader range of patients including all ages, genders, education and socioeconomic statuses to see what barriers that this broader range of patients has to using their electronic portals.
\end{abstract}


PORTALS

\section{Barriers to the Use of Electronic Patient Portals}

\section{Chapter 1 - Introduction}

Ever since the Affordable Care Act, patient portals are a requirement for health care facilities to get reimbursed. Health care facilities are investing a lot of time and money into these portals, but how many patients with portal access are using them (Lazard, Watkins, Mackert, Xie, Stephens, \& Shalev, 2016)? Are patients aware that they have a portal? What are the barriers for the patients that are aware of their portal and are not using them?

\section{Background}

Although the majority of patients are enthusiastic about the use of patient portals, not all patients are actively using the portals or even signed up to use them (Tieu, Sarkar, Schillinger, Ratanawongsa, Lyles, Ralston, \& Pasick, 2015). There have been many studies to establish why these portals are not being used since they are so beneficial to patients. Portals allow patients access to past health records, doctor visit summaries, laboratory results and enable them to make or change appointments, communicate monitoring results, and ask or respond to a provider's question (Tieu et al., 2015). According to Lazard et al. (2016), patient health records or portals can improve patient's health outcomes by providing patients access to health information thereby allowing them to manage their health on a higher level. Powell's (2017) literature review showed that many patients are not aware that they have access to a portal. According to Tieu et al. (2015), some of these barriers are related to technology issues. Most patients reported having some access to a computer, whether it is a tablet or smartphone, going to a public facility that offers free access, or using a friend or relative's computer (Tieu et al., 2015). One common barrier for patients is anxiety and/or problems remembering or establishing usernames and passwords that are required to set up and access portals (Tieu et al., 2015). Some patients do not 
understand the lingo that is used to set up a secure password and username (Tieu et al., 2015). Cafazzo et al. (2012) say that patients often have a hard time navigating the portal or find that the system is slow due to the Internet speed, causing more frustration. Tieu et al. (2017) found that patients with "limited health literacy required 2 additional minutes to complete each task and were more likely to experience each type of navigational barrier" (Tieu et al., 2017, p. e47). Tieu et al. (2017) go on to say that patients with limited health literacy have trouble typing, understanding health acronyms, understanding laboratory tests and medication names. Lazard et al. (2015) did a study that showed that the aesthetics of the portal played an important part in whether patients revisited their portal. Lazard et al (2015) report that even when there are flaws in the portal, patients are more likely to use the portal over a longer period of time when the portal is "visually acceptable" and simple. Lazard et al. (2015) research revealed, “...the visual appeal or aesthetics, has a significant impact on users' emotional and rational evaluations of e-health applications, especially as regards to the users' involvement in the application, the application's perceived usability, the user' trust in the application, and the application's credibility." (Lazard et al., p. e157, paragraph 3, 2015).

Another common barrier for patients is the lack of trust in the security of the information that is contained in their portals. The news media often reports on breaches within major companies, which adds to the fear of having their information accessed illegally. Powell's (2017) literature review showed that patients were concerned about the possibility of their information being obtained by hackers or their passwords being stolen. Tiddy (2015), points out that patient health information is already in electronic format through the use of Electronic Health Records (EHR) in the health care setting, so there is no reason not to take advantage of their portals.

Some non-technical barriers associated with patients not using their portals is that patients feel that their health is under control and do not feel a need to report their self- 
monitoring results (Cafazzo et al., 2012). They see that the results are normal and do not want to spend the time and effort to enter them into the portal. Cafazzo et al. (2012) also found that patients reported that it takes them too much time since there was a certain degree of difficulty entering their results into the portal. Tieu et al. (2015) found that patients prefer to speak to their provider on the phone because they like the person-to-person contact and that this is what they have been doing in the past. Patients report that the response time is quicker when they make the phone call over logging in to the portal, which often times has a 48-hour turnaround. Patients often think that the portal is like text messaging and expect a quicker response thereby causing them anxiety and frustration.

Patient portals are an important part of the present and future of health care. As time goes on, more patients will be aware of their portal and find it useful. According to Powell (2017), electronic portals have "been found to build trust between the patient and the provider". Health care facilities can help by informing patients that they have a portal at every opportunity and assisting them with the process. Vendors can help by creating software that is easy to use and visually pleasing.

\section{Purpose of Study}

This study set out to identify the reasons why patients are not using their electronic portals. The literature shows that older patients and lower socioeconomic status are less likely to use portals, but what about the younger population and the upper and middle-class patients? Are they using their portal? Once the barriers are identified, solutions can be provided to offset these barriers and increase electronic portal use.

\section{Significance of Study}

Health care technology is here to stay, and electronic patient portals are a mainstay of health care. If these portals are not being used, the benefits that they provide will be useless. Patient's 
health can be positively affected by using portals for communication and disease maintenance. Healthier patients lead to better reimbursement. The barriers to using a portal should be identified and rectified so that all patients can reap the positive health benefits. This study can help to identify trends in portal usage when repeated periodically.

\section{Research Questions}

Which patients are using their electronic portals?

What are some of the barriers for patients not using their electronic portal?

Are younger patients more likely to use electronic portals?

Do patients with in a higher education level use their portals?

\section{Limitations}

The sample population may not represent all patient types since access to individuals that do not utilize health care may be limited. This may lead to sicker patients responding to the questionnaire and they tend to be older patients. Time and money do not permit an in-depth interview with each patient so a questionnaire will be used to access the information. The questionnaire will be in a multiple-choice or short answer format that may lead the patient to choose an answer presented on the form even when their choice is not on the list. Patients may not understand the question or not know what an electronic patient portal is. There is a possibility of selection bias in which patients that are aware of portals may respond more than persons who do not know what a portal is. Patients that prefer digital technology over paper may not participate using a paper format. 


\section{Chapter 2 - Review of the Literature}

\section{Review of the Literature}

A literature review was performed to identify the research that has already been performed on the subject of barriers to patient portal use and to home in on where more research is needed. The methods used to research, and the findings are presented here.

\section{Materials and Methods}

Identification of articles. A literature review was performed using PubMed, Cumulative Index to Nursing and Allied Health Literature (CINAHL), and Google Scholar search engine. The research was conducted using combinations of key terms such as barriers, patient, electronic and portal. A research librarian at University of Tennessee Health Science Center was consulted to assist in a thorough search of relevant articles.

Inclusion and exclusion criteria. The research was limited to studies done in the years 2014 through 2018 to capture the most current information. Studies done outside of the United States were excluded because the health care system and portals are not known or unlikely to be the same. The eight articles reviewed are from primary sources that exclude articles pertaining to the clinician or clinic employee's view of patient's barriers to portal use.

\section{Populations Studied}

The literature review included studies on all patients, but most of the articles focused on the elderly, low income, and minority patients. The participants of most studies were 50 years old and up. Two studies limited their participants to veterans or their caregivers (Haun et al., 2014 and Mishuris et al., 2015). One study included only patients with diabetes (Tieu et al., 2015). Irizarry et al. (2017), like all of the reviewed studies, included older adults but their participant's demographics were a mix of incomes and races. One study only used participants that had a chronic illness and did not include the patient's income (Tieu et al. (2017). 


\section{Results}

The initial search in PubMed produced 117 articles and CINAHL produced 51 articles in which they were reviewed for duplicate information, data collected outside the date range, and irrelevant information. The final number of articles that remained totaled 17 from all sources. After a thorough review of the 17 articles, 9 articles were excluded for reasons of date out of range, irrelevant information, out of the United States, or duplicate information. This resulted in 8 articles included in the review.

\section{Findings}

It is often thought that the biggest barrier to patients using their electronic portals is security, but upon review of the literature, it was not the most reported barrier although security was one of the top three concerns (Table 1). According to the articles reviewed, technology issues are the most reported barriers to using electronic portals. Patients have a hard time remembering passwords and navigating the portals. The cost of having computer and Internet access was a concern in some studies but not in the majority of the studies. An important barrier for some patients is the difficulty they have when it comes to understanding and interpreting the medical content (Tieu, et al., 2017). Haun et al. (2014) find that some patients indicated that the health care provider showed some resistance to patients using their electronic portals. Another common barrier found in six out of the seven studies was the need for face-to-face contact with the provider. Many patients do not want to change the way that they have been receiving health information and prefer the personal connection they get from face-to-face interactions. 
Table 1 - Comparison of Studies Reviewed

\begin{tabular}{|c|c|c|c|c|c|c|}
\hline Study & Participants & Barriers & Cost & Secure & Tech & Face \\
\hline $\begin{array}{l}\text { Alpert, J. M., } \\
\text { Krist, A. H., } \\
\text { et al. (2016) }\end{array}$ & $\begin{array}{l}-44 \text { of various } \\
\text { ages }\end{array}$ & $\begin{array}{l}\text {-Medical literacy } \\
\text { - Log-in issues }\end{array}$ & & & $\sqrt{ }$ & $\sqrt{ }$ \\
\hline $\begin{array}{l}\text { Haun, J. N., } \\
\text { Lind, J. D., et } \\
\text { al.(2014) }\end{array}$ & $\begin{array}{l}\text {-32 veterans } \\
\text {-Older white } \\
\text { males } \\
\text {-Mean age } 59.5\end{array}$ & $\begin{array}{l}\text {-Initiation \& } \\
\text { knowledge } \\
\text { barriers } \\
\text {-Privacy and } \\
\text { security } \\
\text {-Not personal } \\
\end{array}$ & & $\sqrt{ }$ & $\sqrt{ }$ & $\sqrt{ }$ \\
\hline $\begin{array}{l}\text { Mishuris, R. } \\
\text { G., Stewart, } \\
\text { M., et al. } \\
\text { (2015) }\end{array}$ & $\begin{array}{l}-14 \text { veterans } \\
-13 \text { men and } 2 \\
\text { women } \\
\text {-Age } 55 \text { and up }\end{array}$ & $\begin{array}{l}\text {-Limited } \\
\text { knowledge } \\
\text {-Satisfied with } \\
\text { current procedure } \\
\text {-Computer access } \\
\text { issues }\end{array}$ & & & $\sqrt{ }$ & $\sqrt{ }$ \\
\hline $\begin{array}{l}\text { Turner, A. } \\
\text { M., } \\
\text { Osterhage,K., } \\
\text { et al. (2015) }\end{array}$ & $\begin{array}{l}\text {-74 participants } \\
\text {-Age } 60 \text { and up } \\
-80 \% \text { white }\end{array}$ & $\begin{array}{l}\text {-Lack of computer } \\
\text { proficiency } \\
\text {-High internet } \\
\text { costs } \\
\text {-Security }\end{array}$ & $\sqrt{ }$ & $\sqrt{ }$ & $\sqrt{ }$ & \\
\hline $\begin{array}{l}\text { Latulipe, C., } \\
\text { Gatto, A., et } \\
\text { al. (2015) }\end{array}$ & $\begin{array}{l}\text {-52 participants } \\
\text {-Low-income } \\
\text { adults } \\
\text {-Minorities } \\
\text {-Age } 55 \text { and } u\end{array}$ & $\begin{array}{l}\text {-Internet not } \\
\text { affordable } \\
\text {-Trust } \\
\text {-Face-to-face } \\
\text { encounters }\end{array}$ & $\sqrt{ }$ & $\sqrt{ }$ & $\sqrt{ }$ & $\sqrt{ }$ \\
\hline $\begin{array}{l}\text { Tieu, L., } \\
\text { Sarkar, U., et } \\
\text { al. (2015) }\end{array}$ & $\begin{array}{l}\text {-16 participants } \\
-63 \% \text { male } \\
-50 \% \text { African } \\
\text { American } \\
\text {-All had diabetes } \\
\text {-Age } 50 \text { and up }\end{array}$ & $\begin{array}{l}\text {-Technology skills } \\
\text {-Security and } \\
\text { privacy } \\
\text {-Face-to-face } \\
\text { interactions } \\
\text {-Computer or } \\
\text { internet access }\end{array}$ & & $\sqrt{ }$ & $\sqrt{ }$ & $\sqrt{ }$ \\
\hline $\begin{array}{l}\text { Tieu, L., } \\
\text { Schillinger, } \\
\text { D., et al. } \\
\text { (2017) }\end{array}$ & $\begin{array}{l}\text {-25 participants } \\
\text {-All had chronic } \\
\text { illness } \\
\text {-Age } 55 \text { and up }\end{array}$ & $\begin{array}{l}\text {-Basic computer } \\
\text { skills } \\
\text {-Navigation issues } \\
\text {-Medical literacy }\end{array}$ & & & $\sqrt{ }$ & \\
\hline $\begin{array}{l}\text { Irizarry, T., } \\
\text { Shoemake J., } \\
\text { et al. (2017) }\end{array}$ & $\begin{array}{l}-100 \text { participants } \\
\text {-Age } 65 \text { and up }\end{array}$ & $\begin{array}{l}\text {-Computer skills } \\
\text {-Fear or } \\
\text { frustration } \\
\text {-Face-to-face }\end{array}$ & & & $\sqrt{ }$ & $\sqrt{ }$ \\
\hline
\end{tabular}




\section{Limitations}

Each study had different inclusion and exclusion protocol for their participants. Some studies included only patients in one health care setting, such as a Veteran's Administration Medical Center. The age of the participants was mostly older adults, so the young population was not adequately represented. Not all patients have the same knowledge and experience with technology.

\section{Conclusion}

This review shows that the lack of technology skills is a large barrier to patients using their electronic portals. According to Tieu et al. (2017), it takes patients who are not technologically savvy almost one and a half times longer to navigate the electronic portal. Faceto-face interactions with a health care provider have a significant impact on patient's use of their portals since they want to keep doing business the way they always have been (Mishuris, 2015). Security of the portals was one of the top five barriers, but it was not the most significant as some may think. Patient portals are an important part of the future of health care. They are integral to the success of streamlining the health care system. As technology progresses, more patients will have access to computers and the Internet, with a projected increase in the use of portals. The children of today are brought up using technology, so the barriers of not knowing how to navigate a computer and portal will assumingly decrease. Future studies can involve a broader range of patients, including the younger population to observe if they have any barriers to portal use. Continued monitoring of electronic portal usage is important in order to observe whether or not the number of patients not using their portal is declining and to offset any barriers that the research presents. 


\section{Chapter 3 - Methodology}

\section{Methodology}

The methods used to recruit participants and collect data for this study and an explanation as to why they were chosen.

\section{Research Design}

The research design utilized structured questions in a paper questionnaire format. The questionnaire was made available to patrons at a local pharmacy in order to reach potential participants, including those that do not have access to technology. A search of the literature did not show that a survey or questionnaire is available with the specifics that will be needed for this research project; therefore, a questionnaire was created based on the necessary information. A simple random sampling method will be used.

\section{Population and Sample Design}

A questionnaire was performed to obtain data from individuals of the population as a whole. A large sample size is needed in order to obtain a representation of a population of all ages, gender, education and socioeconomic status.

\section{Data Collection Procedures}

A close-ended questionnaire (Appendix B) was made available to individuals that visit a medium, local independent pharmacy. The pharmacy has been established for more than 40 years in the Nashville, TN area and is situated in a strip mall that has retail and restaurant anchor stores. The pharmacy has front area that provides over-the-counter medication, snacks and gifts. The pharmacy provides immunizations and compounding along with filling medication orders.

Patrons of the pharmacy were either approached and verbally requested to participate or a sign (Appendix C) asking for their participation was presented to them at the pharmacy counter at times when the investigator was not present. The questionnaire was left on display at the 
pharmacy counter for two weeks and the investigator was present on two occasions after which the papers were collected and evaluated.

\section{Data Collection Instrument}

The instrument chosen for this research project is a questionnaire (Appendix B) that was made available to patients at a local independent pharmacy. The paper questionnaire included a cover sheet (Appendix A) with a definition of a patient electronic portal and what is expected of them if they participate.

\section{Data Analysis}

The questionnaires will be collected and the responses to each question tallied.

\section{Response Rate}

The number of participants is expected to be between $25-50$.

\section{Research Questions}

Questions were formulated based on the barriers identified in the literature review such as:

- Technology issues:

○ Remembering username and passwords

- Navigating the portal to find what is needed

$\circ$ Lack of trust that information is safe

- Non-technical issues:

- Prefer to speak to their provider

- Feel response time is quicker via telephone

- Understanding the language used in the portal

The following is a list of the questions on the questionnaire: (also, see Appendix B)

1. What is your age in years?

2. Are you male or female? 
3. What is your yearly income range?

4. What is your highest education level?

5. Do you know if you have a personal electronic health record or portal that you can access?

6. If you have an electronic health record or portal, where do you access it most of the time?

7. How do you access your electronic health record or portal?

8. Is the language used in your electronic health record or portal easy to understand?

9. Do you have any problem with your username and/or password when logging in to your electronic health record or portal?

10. In your electronic health record or portal, is it easy to find what you are looking for?

11. How many times have you used your electronic health record or portal in the past 6 months?

12. Do you feel that your health information that is contained in your electronic health record or portal is safe?

13. Would you rather contact your provider by phone or your electronic health record?

14. Would you get a faster response from you provider by telephone or by your electronic health record or portal?

\section{Summary of Chapter 3}

A random sample of the population will be obtained by presenting patrons of a small, local independent pharmacy with a closed-ended questionnaire. Results will be quantified and analyzed based on age, gender, socioeconomic status and education level. 


\section{Chapter 4 - Results}

\section{Results}

The data from the questionnaires were analyzed and the results were grouped and compared, each separately with age, gender, income level and education level.

\section{Response Rate of Population}

Twenty-eight patrons of the pharmacy participated in the two-week time frame.

\section{Profile of Population}

After evaluation, the general profile of participants was found to be a graduate with an income level above $\$ 35,000$. Males predominated over females. The age range was 24 to 84 years old with a mean age of 45 .

\section{Results of Research Questions}

Do you have a portal? Most participants acknowledged having a portal. The exception is the $65+$ age group where no participant acknowledged having a portal. All participants in the 18-35 age range are aware of their portal and age range 36-64 the majority are aware (Graph 1).

\section{Graph 1 Do You Have a Portal? By Age Group}

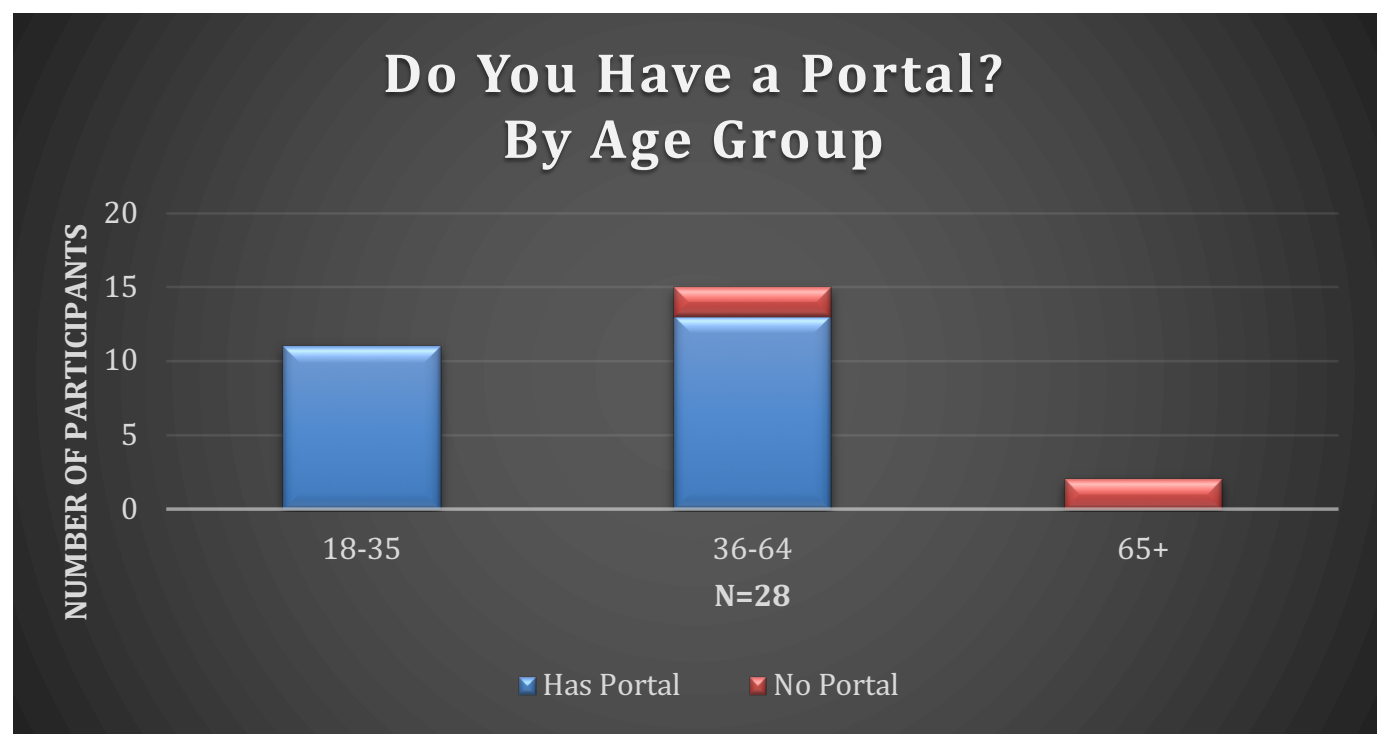


Even though more females ( $92 \%$ vs $81 \%$ ), are aware that they had a portal than not, males have a greater percentage that are aware than not aware (Graph 2).

Graph 2 Do You Have a Portal? By Gender

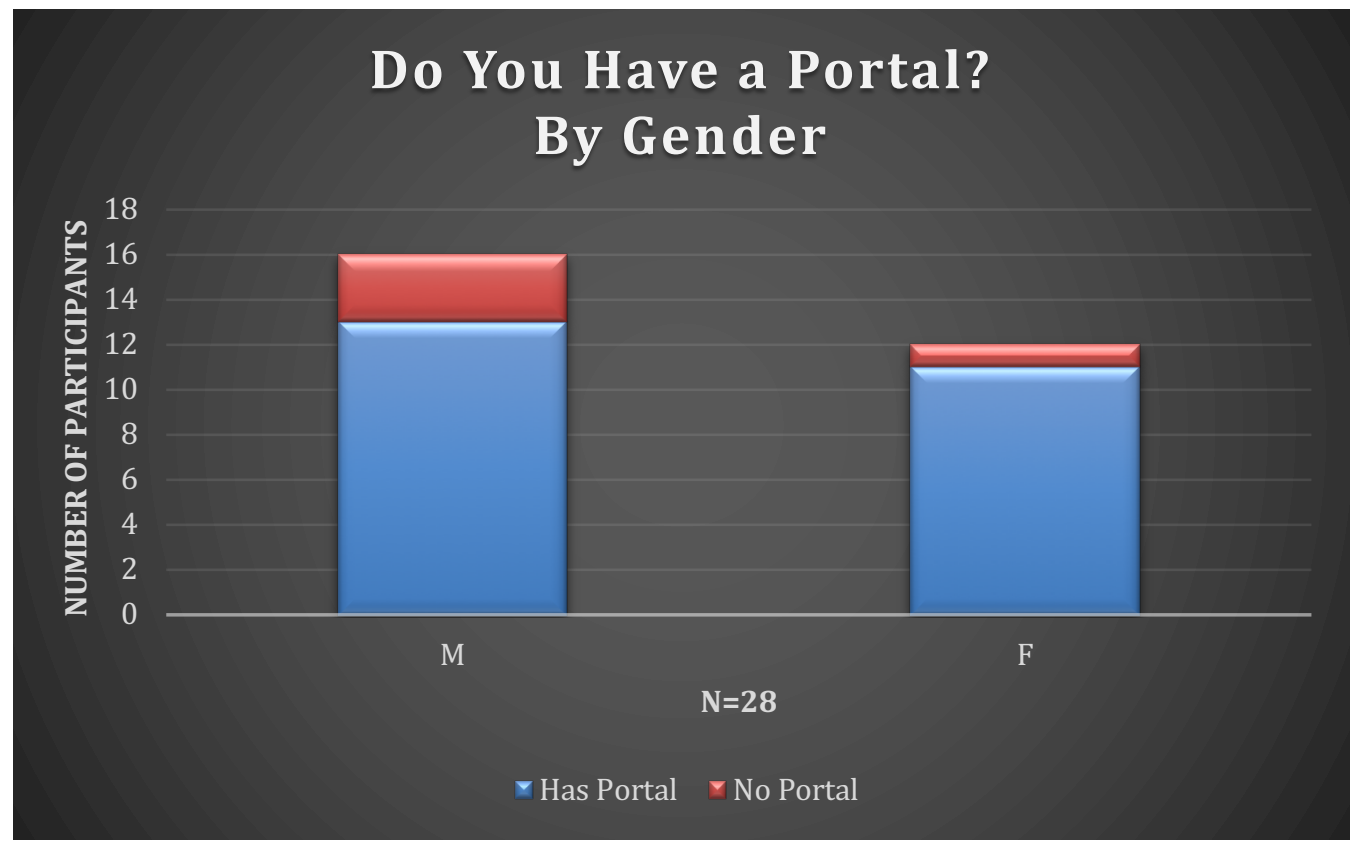

Participants that are in the $>\$ 100,000$ income level are more likely to acknowledge their portal and the $\$ 35,000$ - $\$ 99,999$ level are more likely to deny theirs (Graph 3).

Graph 3 Do You Have a Portal? By Income Level

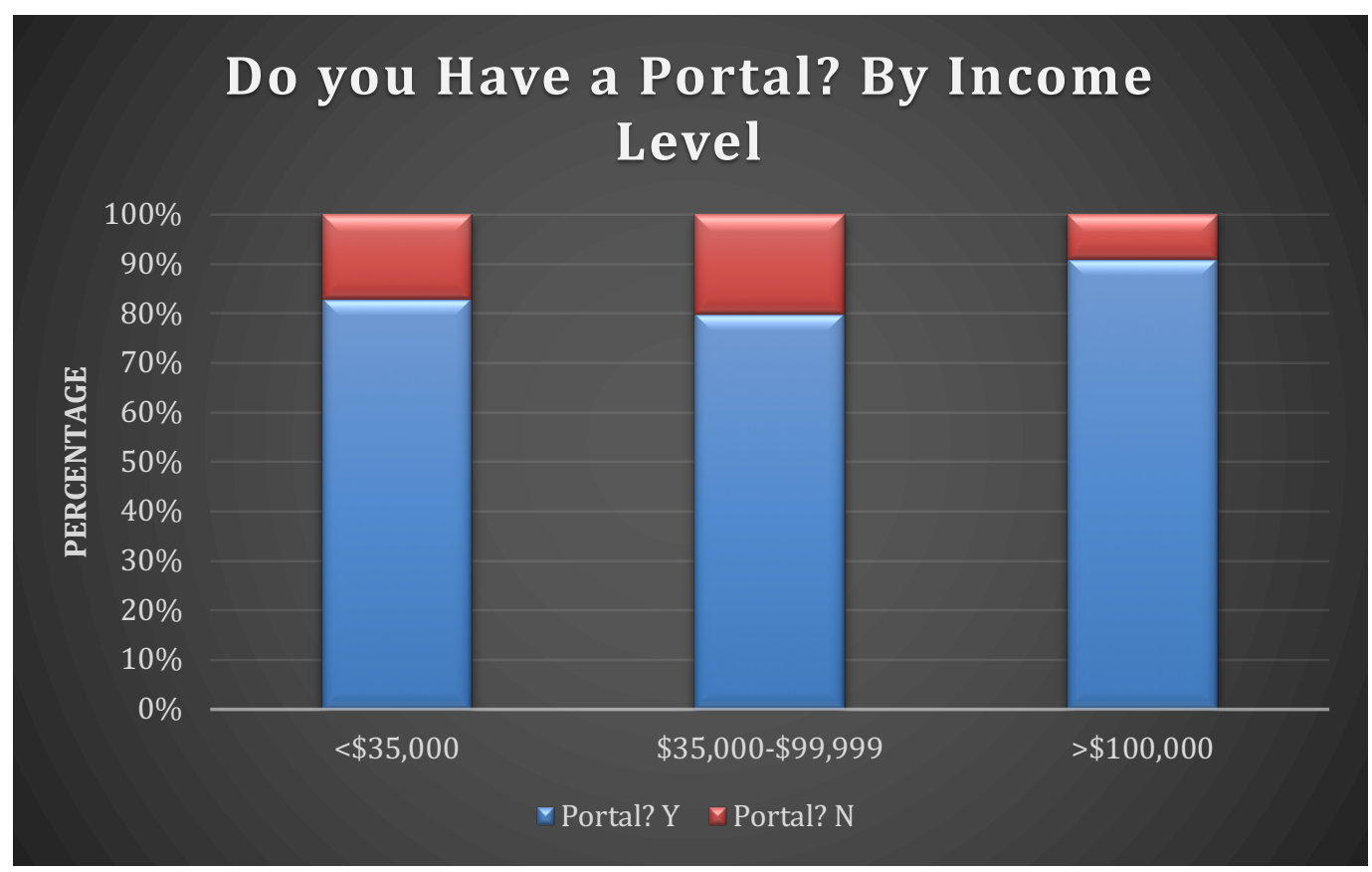


Participants with a Some college had the highest denial of a portal and all participants with a bachelor's degree and those with a high school education are aware of their portal (Graph 4). The majority of graduate degree level (77\%) are aware of their portal.

Graph 4 Do You Have a Portal? By Education Level

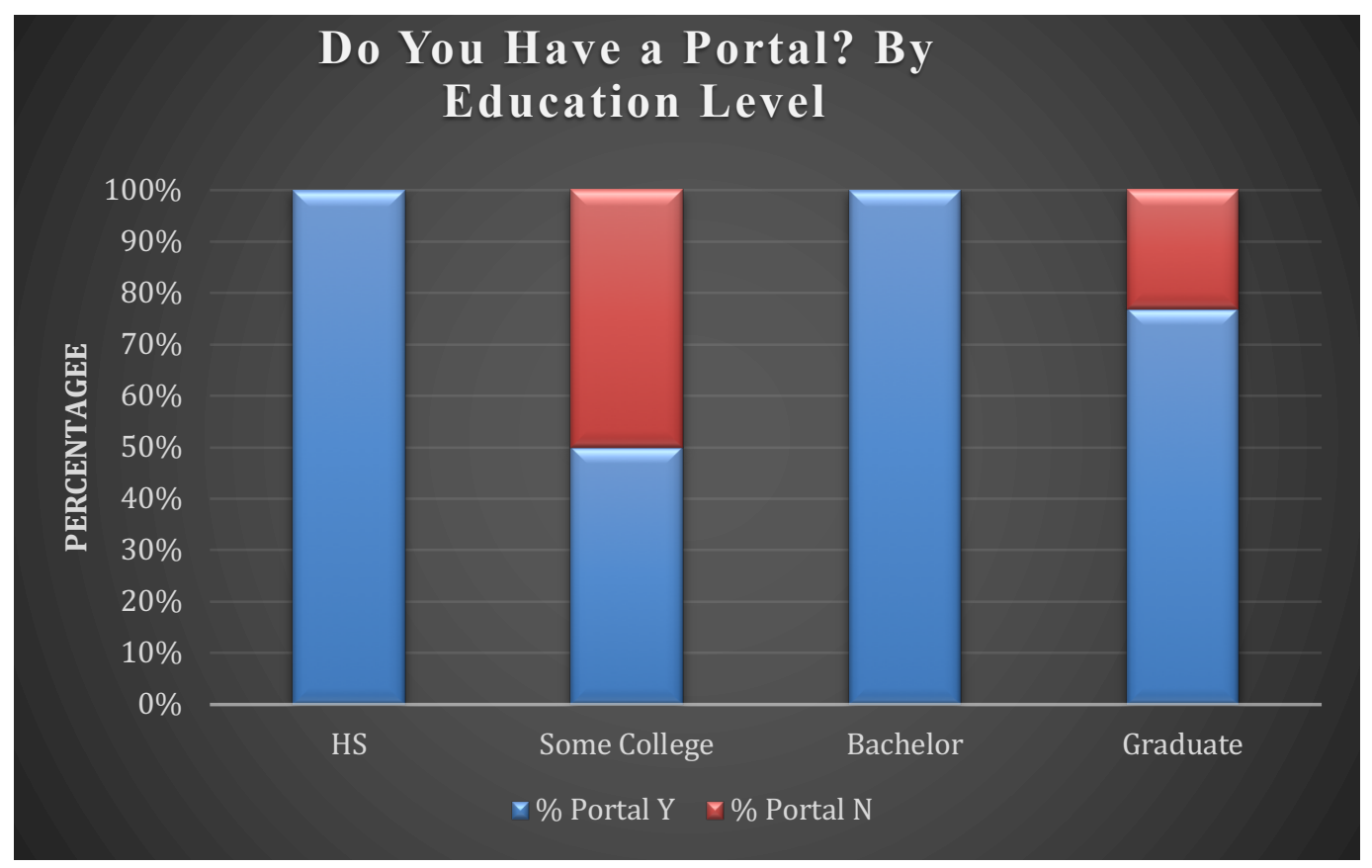

How often do you access your portal? The results show the number of times the portal was accessed by the participant in a 6-month period. Many participants accessed their portal more than one time and others did not access it at all. Participants self-reported the number of times they that they accessed their portal.

Portal access by age group: Graph 5 shows that portals are accessed more often by the youngest age group and decreases as participants age increases. Participants in age group 18-35 accessed their portal 11 more times in six months than the older age group 36-63. Note: participants aged 65 and older denied they had access to a portal. 
Graph 5 How Often Portal Accessed in Six Months - By Age

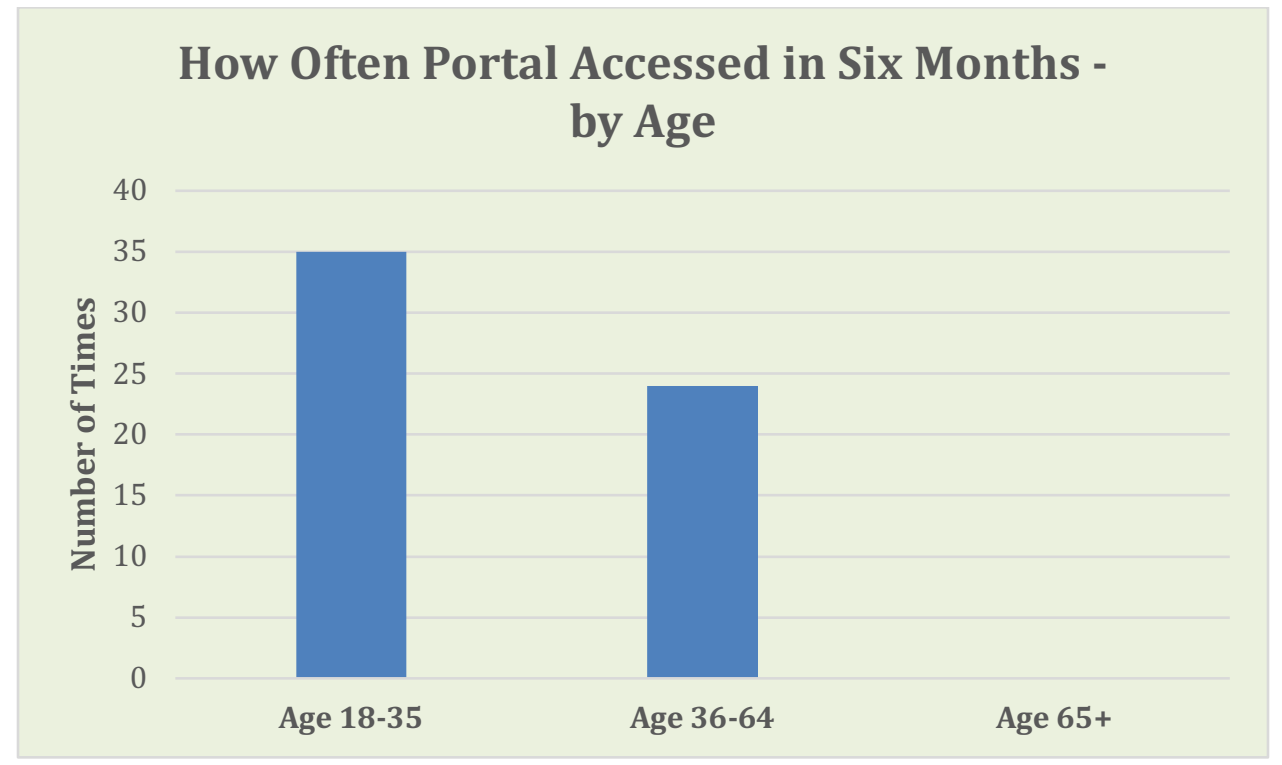

Portal access by gender: As shown in Graph 6, females access their portal significantly more often than males.

Graph 6 How Often Portal Accessed by Gender

\section{How Often Portal Accessed by Gender}

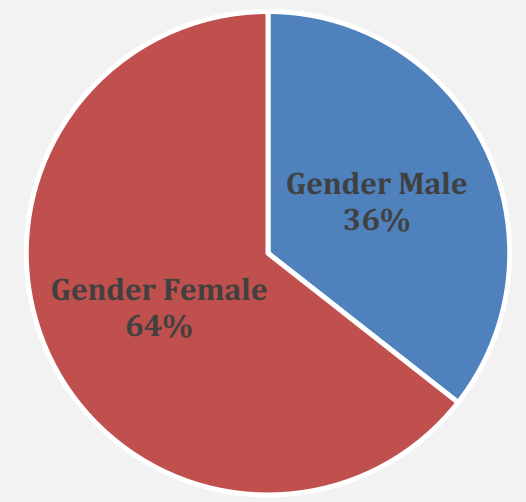

- Gender Male - Gender Female

Portal access by income level: As shown in Graph 7 participants with an income of $\$ 35,000$ to $\$ 99,000$ accessed their portal significantly more often than income levels lower or higher. 
Graph 7 How Often Portal Accessed by Income Level

\section{How Often Portal Accessed by Income Level}

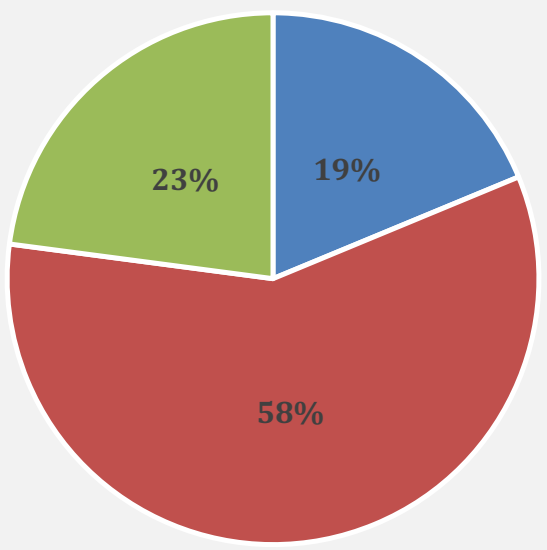

- Income $<\$ 35,000$ - Income $\$ 35,000$ to $\$ 99,000$ Income $>\$ 100,000$

Portal access by education level: Graph 8 shows that participants with a bachelor's degree used their portal the most often. Those with a graduate degree had the second highest. Participants with an associate degree or some college accessed their portal significantly less. None of the High School educated participants accessed their portal. 


\section{Do you feel your information is safe?}

Information safe by age: Graph 9 displays that over half of the participants in the 18-35 and the 35-64 age groups that reported having a portal feel that the information contained in their portal is safe. The youngest age group are more likely to trust the safety of their information in a portal. (Note: the $65+$ age group did not have any participants that acknowledged having a portal). The difference between participants in the 36-64 age group that felt their information was safe (54\%) was not much higher than the ones who did not $(46 \%)$.

Graph 9 Information Safe? By Age Group

\section{Information Safe? By Age Group}

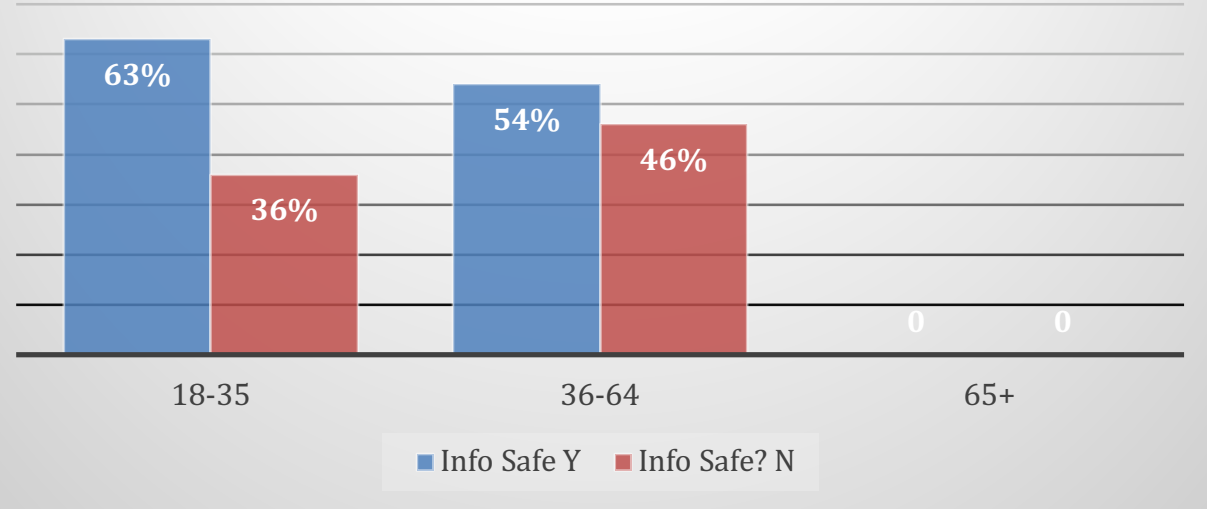


Information safe by income: Graph 10 shows that more than half of the participants in the $<\$ 35,000$ level and the $\$ 35,000$ to $\$ 99,9999$ level feel that their information is safe. Participants in the income level of $>\$ 100,000$ are evenly split.

Graph 10 Information Safe? By Income

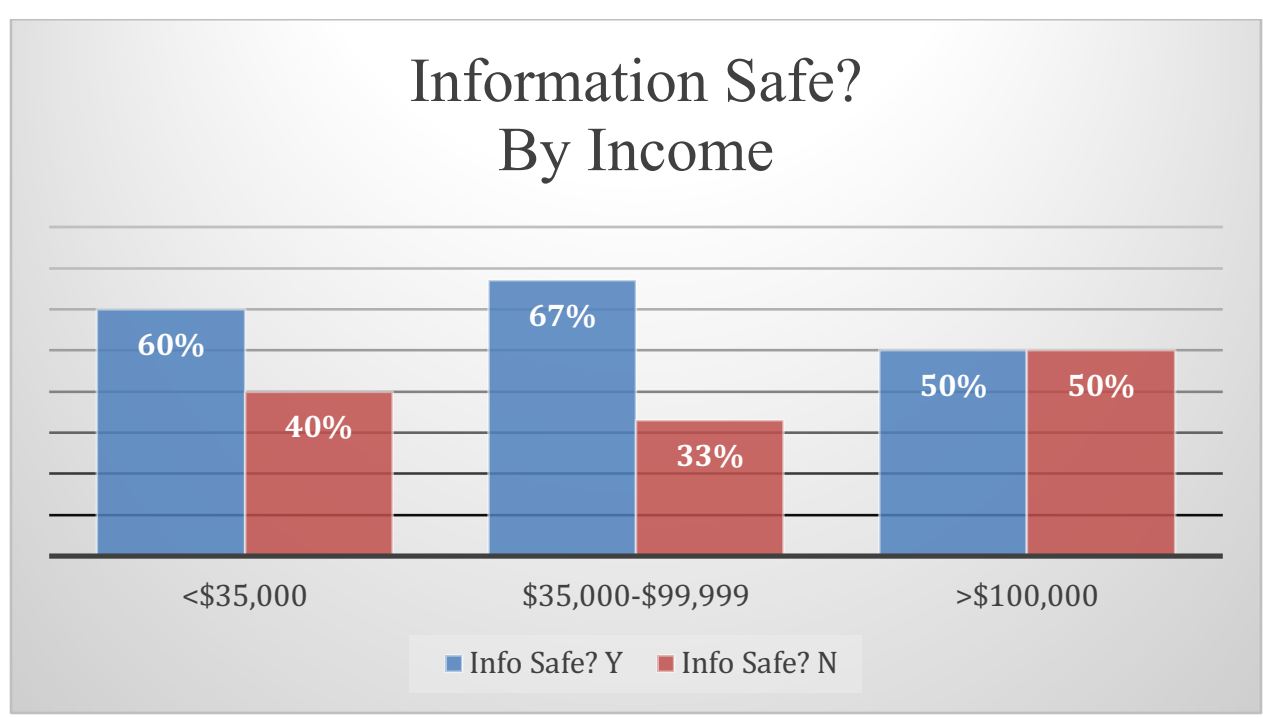

Information safe by gender: Graph 11 shows that females feel the information in their portal is safe compared to males. There is a larger gap between trusting and not trusting in female participants than the males.

Graph 11 Information Safe? By Gender

\section{Information Safe? By Gender}

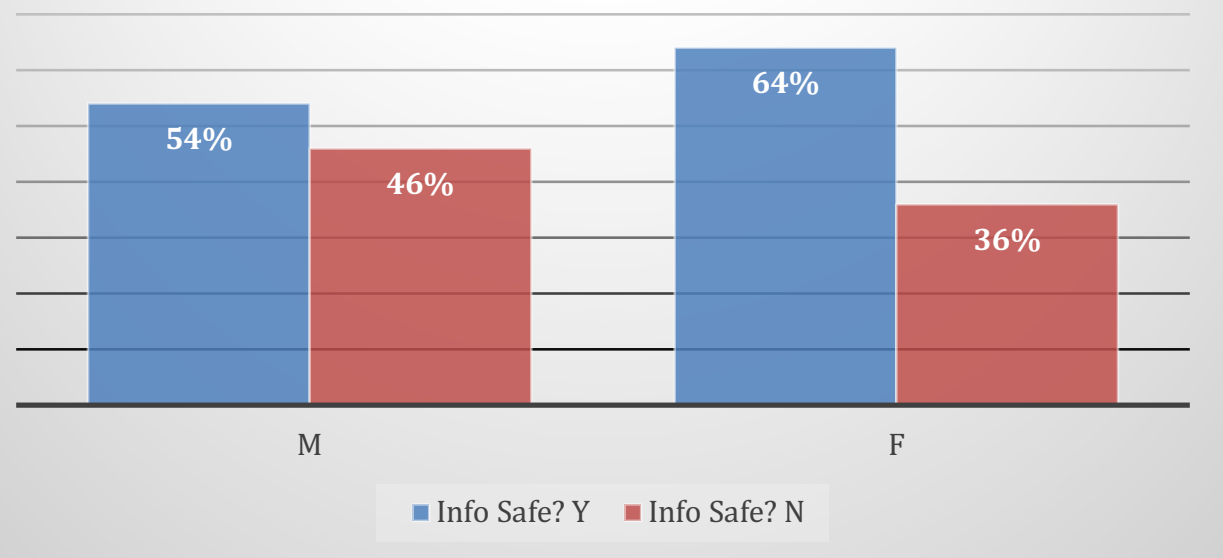


Information safe by education level: Graph 12 shows that all of the participants on a high school and associate level feel that their information is not safe where all the participants that have some college education feel that their information is safe. Most of the bachelor level participants $(81 \%)$ feel that their information is safe whereas less than half $(40 \%)$ of the graduate level participants felt their information was safe.

Graph 12 Information Safe? By Education

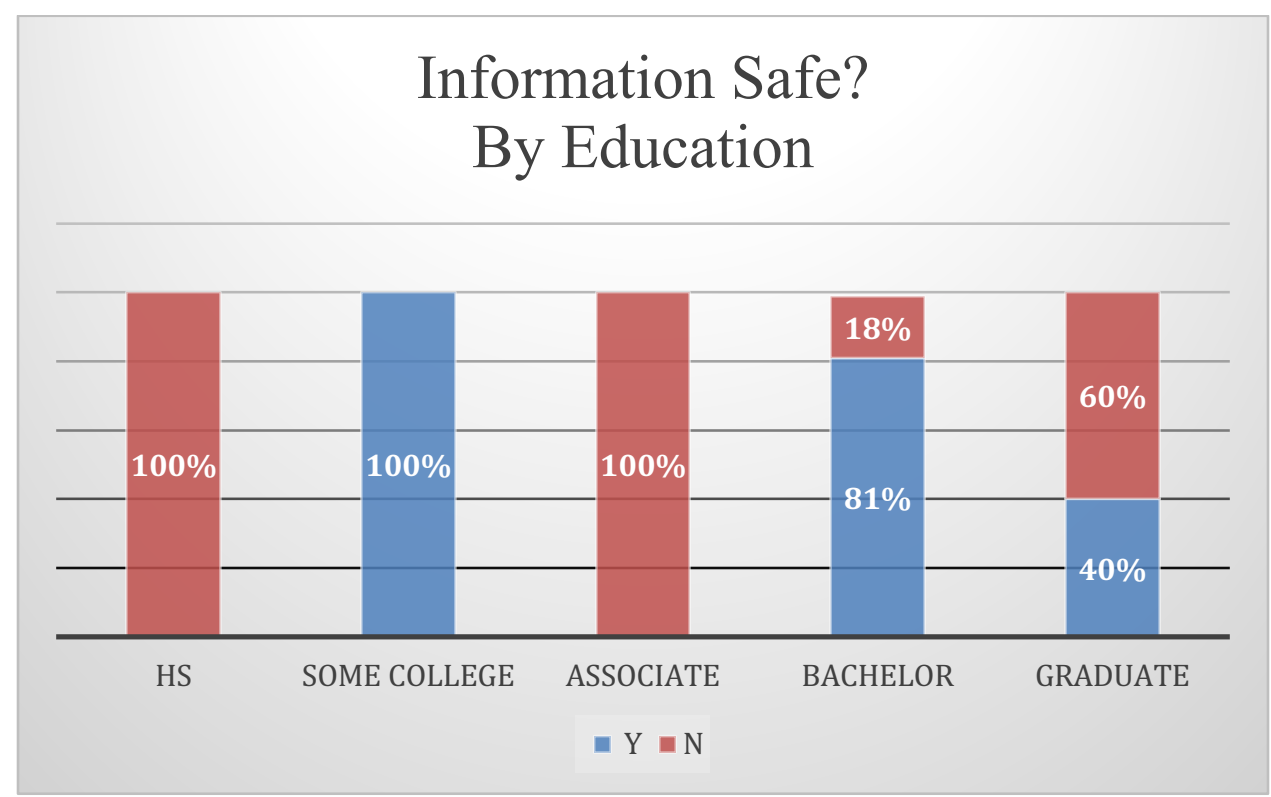


Problems using the portal (See Table 2)

Problems by age group: Table 2 shows that most participants in the $36-64$ age group had a harder time using their portal. This group was more likely to find the language difficult, information hard to find and had username and/or password problems. Participants from the 65 plus age group denied having a portal so none are included.

Table 2 Problems Using the Portal

\begin{tabular}{|c|c|c|c|}
\hline AGE GROUP & $\begin{array}{c}\% \text { FIND } \\
\text { LANGUAGE } \\
\text { DIFFICULT }\end{array}$ & $\begin{array}{l}\text { \% USERNAME/ } \\
\text { PASSWORD } \\
\text { PROBLEMS }\end{array}$ & $\begin{array}{l}\text { \% INFORMATION } \\
\text { HARD TO FIND }\end{array}$ \\
\hline 18-35 & 0 & 0 & 9 \\
\hline $36-64$ & 8 & 46 & 29 \\
\hline $65+$ & ND & ND & ND \\
\hline GENDER & $\begin{array}{c}\% \text { FIND } \\
\text { LANGUAGE } \\
\text { DIFFICULT }\end{array}$ & $\begin{array}{l}\text { \% USERNAME/ } \\
\text { PASSWORD } \\
\text { PROBLEMS }\end{array}$ & $\begin{array}{l}\text { \% INFORMATION } \\
\text { HARD TO FIND }\end{array}$ \\
\hline M & 8 & 6 & 12 \\
\hline $\mathbf{F}$ & 0 & 33 & 25 \\
\hline INCOME & $\begin{array}{c}\% \text { FIND } \\
\text { LANGUAGE } \\
\text { DIFFICULT }\end{array}$ & $\begin{array}{l}\text { \% USERNAME/ } \\
\text { PASSWORD } \\
\text { PROBLEMS }\end{array}$ & $\begin{array}{l}\text { \% INFORMATION } \\
\text { HARD TO FIND }\end{array}$ \\
\hline$<\$ 35,000$ & 0 & 0 & 17 \\
\hline $\begin{array}{l}\$ 35,000- \\
\$ 99,999\end{array}$ & 0 & 9 & 9 \\
\hline$\$ 100,000$ or $>$ & 9 & 45 & 27 \\
\hline $\begin{array}{l}\text { EDUCATIO } \\
\mathbf{N}\end{array}$ & $\begin{array}{c}\% \text { FIND } \\
\text { LANGUAGE } \\
\text { DIFFICULT }\end{array}$ & $\begin{array}{l}\text { \% USERNAME/ } \\
\text { PASSWORD } \\
\text { PROBLEMS }\end{array}$ & $\begin{array}{l}\text { \% INFORMATION } \\
\text { HARD TO FIND }\end{array}$ \\
\hline Highschool & 0 & 36 & 0 \\
\hline Some College & 0 & 15 & 0 \\
\hline Associate & 0 & 0 & 100 \\
\hline Bachelor & 9 & 0 & 36 \\
\hline Graduate & 0 & 0 & 0 \\
\hline
\end{tabular}


Problems by gender: Females are more likely to have problems with username and passwords and feel that the information in their portal was hard to find compared to males. Some males did have problems but not as prominent as females. Males found the language difficult where females did not.

Problems by income level: All income levels had participants that reported information in their portal was hard to find. Participants in the $\$ 100,000$ or greater group are more likely to find the language in their portal difficult, have username and or password problems and have a hard time finding the information they needed compared to other income levels.

Problems by education level: Participants with a bachelor's degree found that the language in their portal was difficult compared to other education levels. Participants with a lower level of education found they had problems with their username and or password. Participants with an associate or bachelor's degree found the information they needed in their portal was hard to find.

\section{Do you prefer phone or portal? (See Table 3)}

Phone or portal by age: Participants in the 65 and older age group denied having a portal resulting in no data. Participants in the 35-64 age group preferred to contact their provider by phone and found that the phone would produce a faster response.

Phone or portal by gender: More male participants preferred to contact their provider by phone compared to females, but females thought the phone would produce a faster response.

Phone or portal by income: Participants in the $\$ 35,000$ to $\$ 99,999$ income level prefer to phone their provider rather than accessing their portal. This income level also feels that the phone will produce a faster response time. More than half of the participants in the greater than $\$ 100,000$ level prefer to contact their provider by phone but less than half feel that the phone is 
faster. Forty percent of participants in the less than $\$ 35,000$ income level prefer to contact their provider by phone even though only twenty percent feel that the portal is faster.

Table 3 Portal or Phone

\begin{tabular}{|c|c|c|}
\hline AGE & $\begin{array}{c}\text { PREFER PHONE OVER } \\
\text { PORTAL } \%\end{array}$ & $\begin{array}{c}\text { PHONE IS FASTER } \\
\%\end{array}$ \\
\hline 18-35 & 42 & 33 \\
\hline $36-64$ & 60 & 47 \\
\hline $65+$ & ND & ND \\
\hline GENDER & $\begin{array}{c}\text { PREFER PHONE OVER } \\
\text { PORTAL \% }\end{array}$ & $\begin{array}{c}\text { PHONE IS FASTER } \\
\%\end{array}$ \\
\hline $\mathbf{M}$ & 62 & 31 \\
\hline $\mathbf{F}$ & 33 & 50 \\
\hline INCOME & $\begin{array}{l}\text { PREFER PHONE OVER } \\
\text { PORTAL } \% \\
\end{array}$ & $\begin{array}{c}\text { PHONE IS FASTER } \\
\%\end{array}$ \\
\hline$<\$ 35,000$ & 40 & 20 \\
\hline$\$ 35,000$ - \$99,999 & 67 & 67 \\
\hline$>\$ 100,000$ & 60 & 40 \\
\hline EDUCATION & $\begin{array}{l}\text { PREFER PHONE OVER } \\
\text { PORTAL } \%\end{array}$ & $\begin{array}{c}\text { PHONE IS FASTER } \\
\%\end{array}$ \\
\hline Highschool & 100 & $\mathbf{0}$ \\
\hline Some College & $\mathbf{0}$ & $\mathbf{0}$ \\
\hline Associate & 100 & $\mathbf{0}$ \\
\hline Bachelor & 45 & 55 \\
\hline Graduate & 60 & 50 \\
\hline
\end{tabular}

Phone or portal by education: Participants with high school and some college education levels preferred the phone over using their portal. Participants with a bachelor's degree are the most likely to use their portal to contact their provider. Only bachelor's degree and graduate level participants feel that using the phone would produce a faster response. 


\section{Summary of Chapter}

Results were analyzed and the report compared participants ages, genders, income levels and education levels to each of the questions presented in the questionnaire.

The general profile of a male in this study is 46 years old, holds a graduate degree and earns over $\$ 100,000$ per year. He acknowledges having a portal but does not access it very often. He feels that the portal does not present any problems with language, user name, passwords or finding information. A typical male in this study prefers to use the phone to contact their provider but feels that the portal receives a faster response. The males in this study feel that the information in his portal is safe but could easily switch views.

The general profile of a female in this study is one that is 44 years old, holds a bachelor's degree and is in the $\$ 35,000$ to $\$ 99,999$ income range. She knows she has a portal and accesses it. She feels that her information is safe but finds it hard to locate information and has problems with the username or password. She prefers using the portal instead of a phone and is unsure whether the phone or portal is faster. 


\section{Chapter 5 - Conclusions and Recommendations}

\section{Summary of Findings}

This study shows that younger participants used their portals more often than older participants. All participants in the $65+$ age range denied having a portal. Due to their age, younger patients typically tend to have fewer medical encounters than the older population. Based on this knowledge, this study could be interpreted to indicate that the younger population use their portals to manage their health while the older population are still using traditional ways (i.e. phone or face-to-face).

A larger than expected number of participants are aware that they had a portal. Most participants accessed the portal on their own device (computer, smartphone, or tablet) at home.

Fifty percent of the top users ( 3 or more uses in 6 months) of portals said they preferred phoning their provider but utilized their portal to communicate instead. Future studies could home in on why these patients prefer to utilize the phone and why they are using their portal instead. Five out of the eight top users (3 or more uses in 6 months) of portals said that the portal is faster than calling.

This study showed that the younger population are more likely to trust the safety of their information in portals. This can be interpreted as the younger generation is being raised on technology and feel more comfortable with trusting the safety of their information in electronic portals. Duplicating this study in a few years will show if this is truly the trend.

\section{Conclusions}

This study was small and did not include a diverse sample of the general population. Many participants had higher education and not enough participants are in the 65+ age group. It was shown that most participants are aware of having a portal but in general still prefer to contact the provider via phone. This study showed that the majority of participants had access to 
an electronic device and did not rely on outside sources such as a library, friend, or doctor's office to access their portal. This may not be the case if more participants in the lower socioeconomic level or education level are included. Most of the participants did not feel that the language in their portal was difficult, but many did have problems with the username and/or passwords. Information in the electronic portal was hard to find for some groups of participants. With this knowledge, vendors can focus on these issues to make portals easier to navigate and improve the language used in them.

More younger participants (18-35 age group) felt their information was safe in a portal compared to the 36-64 age group. Trends can be monitored by using this facet since all three age levels are predicted to increase due to the shift in participants to the next age group and that technology is incorporated into lives at an earlier age.

\section{Recommendations}

This research study will aid physicians, health care facilities, vendors, Health care informatics professionals etc. to discern why patients are not using their electronic health portals. The barriers to patients using their portal are identified in order to address and rectify. It is hypothesized that the usage of electronic portals will increase over time as younger patients are being brought up in a technology era. This study shows the current trend in electronic portal usage and can be used as a comparison for future research to show whether or not the trend is progressing, stagnating or relapsing. The research questions can be changed, or new ones added as times and technology changes.

Until research shows portal usage is increasing, it is suggested to revisit this topic every three to five years to identify new barriers so that they can be addressed and resolved. Future studies should include a larger population sample to have a better view of trends and issues. 


\section{References}

Alpert, J. M., Krist, A. H., Aycock, R. A., \& Kreps, G. L. (2016). Applying Multiple Methods to Comprehensively Evaluate a Patient Portal's Effectiveness to Convey Information to Patients. JOURNAL OF MEDICAL INTERNET

Haun, J. N., Lind, J. D., Shimada, S. L., Martin, T. L., Gosline, R. M., Antinori, N., ... Simon, S. R. (2014). Evaluating User Experiences of the Secure Messaging Tool on the Veterans Affairs' Patient Portal System. Journal of Medical Internet Research, 16(3), e75. http://doi.org.ezproxy.uthsc.edu/10.2196/jmir.2976 (Primary source).

Irizarry, T., Shoemake, J., Nilsen, M. L., Czaja, S., Beach, S., \& DeVito Dabbs, A. (2017). Patient Portals as a Tool for Health Care Engagement: A Mixed-Method Study of Older Adults With Varying Levels of Health Literacy and Prior Patient Portal Use. Journal of Medical Internet Research, 19(3), e99. http://doi.org.ezproxy.uthsc.edu/10.2196/jmir.7099 (Primary source).

Latulipe, C., Gatto, A., Nguyen, H. T., Miller, D. P., Quandt, S. A., Bertoni, A. G., .. Arcury, T. A. (2015). Design Considerations for Patient Portal Adoption by Low-Income, Older Adults. Proceedings of the SIGCHI Conference on Human Factors in Computing Systems CHI Conference, 2015, 3859-3868.

http://doi.org.ezproxy.uthsc.edu/10.1145/2702123.2702392 (Primary source).

Lazard, A., Watkins, I., Mackert, M., Xie, B., Stephens, K., \& Shalev, H. (2016). Design simplicity influences patient portal use: The role of aesthetic evaluations for technology acceptance. Journal Of The American Medical Informatics Association, 23(e1), e157e161. doi:10.1093/jamia/ocv174 (Primary source). 
Mishuris, R. G., Stewart, M., Fix, G. M., Marcello, T., McInnes, D. K., Hogan, T. P., Boardman, J. B. \& Simon, S. R. (2015). Barriers to patient portal access among veterans receiving home-based primary care: a qualitative study. Health Expectations, 18(6), 2296-2305. doi:10.1111/hex.12199 (Primary source).

Tieu, L., Sarkar, U., Schillinger, D., Ratanawongsa, N., Lyles, C., Ralston, J., \& Pasick, R. (2015). Barriers and facilitators to online portal use among patients and caregivers in a safety net health care system: A qualitative study. Journal Of Medical Internet Research, 17(12), doi:10.2196/jmir.4847 (Primary source).

Tieu, L., Schillinger, D., Sarkar, U., Hoskote, M., Hahn, K. J., Ratanawongsa, N., \& ... Lyles, C. R. (2017). Online patient websites for electronic health record access among vulnerable populations: portals to nowhere? Journal Of The American Medical Informatics Association, 24(e1), e47-e54. doi:10.1093/jamia/ocw098 (Primary source).

Turner, A. M., Osterhage, K., Hartzler, A., Joe, J., Lin, L., Kanagat, N., \& Demiris, G. (2015). Use of Patient Portals for Personal Health Information Management: The Older Adult Perspective. AMIA Annual Symposium Proceedings, 2015, 1234-1241. (Primary source).

Twiddy, D. (2015). Removing six key barriers to online portal use. Family Practice Management, (JANUARY-FEBRUARY 2015), 26-31. (Secondary source)

Urowitz, S., Wiljer, D., Dupak, K., Kuehner, Z., Leonard, K., Lovrics, E., ... Cafazzo, J. (2012). Improving Diabetes Management With a Patient Portal: Qualitative Study of a Diabetes Self-Management Portal. Journal of Medical Internet Research, 14(6), e158. http://doi.org.ezproxy.uthsc.edu/10.2196/jmir.2265 (Primary source). 


\section{Appendix A - Consent Form}

THE UNIVERSITY OF TENNESSEE

Health Science Center

College of Health Professions

Department of Health Informatics \&

Information Management

920 Madison Avenue, Suite 518

Memphis, TN 38163

Office: (901) 448-6486

Fax: (901) 448-1629

Dear patient,

You are being asked to participate in a research study in which your knowledge and attitude towards your personal electronic health portal (patient portal) will be assessed. People invited to participate in this study must be 18 years of age or older.

Your participation is voluntary and if you choose to not participate or to stop participating at any time, your decision will not result in a penalty or affect your rights. If you decide to take part in this research study, you will complete a short questionnaire that will take about 10 minutes to answer the questions. There is no further procedure required. The investigator will analyze the results.

There are no foreseeable risks associated with this study. Your personal information will not be collected, such as name, date of birth, address, phone number, etc.

Please note that you will likely receive no direct benefit from taking part in this research study but the study will benefit researchers in understanding the reasons that patients do not use their electronic portal. You will not be paid for taking part in this study.

If you have any questions about this research study, you may contact Terrence F Ackerman, Ph. D., UTHSC IRB Chairman at 901-448-4824 or visit the IRB website at http://www.uthsc.edu/research/compliance/IRB/ if you have any questions about your rights as a research subject, or if you have questions, concerns, or complaints about the research.

Thank you,

Debbie Hoza 


\section{Appendix B -Patient Questionnaire (Page 1)}

THE UNIVERSITY OF TENNESSEE

Health Science Center

College of Health Professions

Department of Health Informatics \&

Information Management

920 Madison Avenue, Suite 518

Memphis, TN 38163

Office: (901) $448-6486$

Fax: (901) 448-1629

Patient Portal Questionnaire

According to HealthIT.gov a patient portal or patient electronic health record is "a secure online website that gives patients convenient, 24-hour access to personal health information from anywhere with an Internet connection".

1) What is your age in years?

2) Are you Male or Female? $M$

or $\mathrm{F}$

3) What is your yearly income range?

Less than $\$ 35,000$

$\$ 35,000$ to $\$ 99,999$

Greater than $\$ 100,000$

4) What is your highest education level?

Less than high school degree

High school degree or equivalent (e.g. GED)

Some college but no degree

Associate degree

Bachelor degree

Graduate degree

5) Do you know if you have a personal electronic health record or portal that you can access? Yes or No

*** If you answered No to question 5 then you can stop here.

6) If you have an electronic health record or portal, where do you access it most of the time?

Doctor's office?

Library?

Friend's house?

Home?

Other?

7) How do you access your electronic health record or portal?

Computer?

Smart phone?

Tablet?

Other 


\section{Appendix B- Patient Questionnaire (Page 2)}

THE UNIVERSITY OF TENNESSEE

Health Science Center

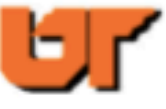

8) Is the language used in your electronic health record or portal easy to understand? Yes or No

9) Do you have any problem with your username and/or password when logging in to your electronic health record or portal? Yes_ or No

10) In your electronic health record or portal is it easy to find what you are looking for? Yes or No

11) How many times have you used your electronic health record or portal in the past 6 months?

12) Do you feel that your health information that is contained in your electronic health record or portal is safe? Yes or No

13) Would you rather contact your provider by phone or your electronic health record? Phone Electronic record

14) Would you get a faster response from your provider by telephone or by your electronic health record or portal?

Phone Electronic health record 
BARRIERS TO THE USE OF ELECTRONIC PATIENT

PORTALS
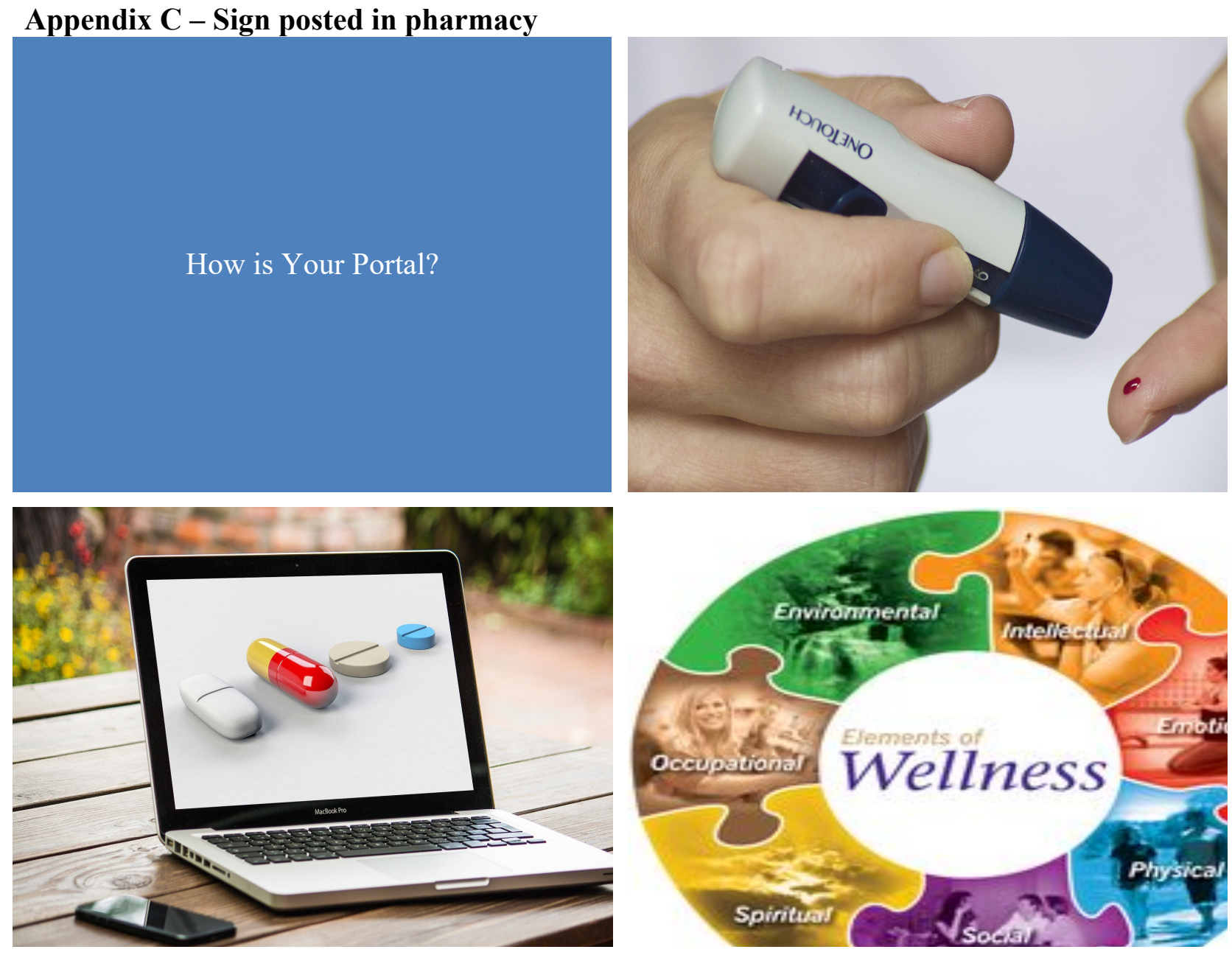

\section{Patient Portal}

Whether you have one or not (or even know what one is), please take a minute to fill out the questionnaire as your contribution

to the research for the betterment of healthcare. 